\title{
Non-covalent functionalization of CVD-grown graphene with Au nanoparticles for electrochemical sensing application
}

\author{
Indrajit Shown ${ }^{1} \cdot$ Abhijit Ganguly ${ }^{1}$
}

Received: 25 June 2016/Accepted: 28 July 2016/Published online: 4 August 2016

(C) The Author(s) 2016. This article is published with open access at Springerlink.com

\begin{abstract}
Graphene is an one-atom thick two-dimensional (2D) transparent carbon sheet which has aroused potential interest for the ultrafast high-sensitive electronic device application. Functionalization of 2D graphene is one of the important aspects to manipulate its intrinsic properties achieving the requisite aptness for its booming applications. Here, a novel strategy for the noncovalent surface functionalization of 2D graphene layer has been proposed utilizing self-assemble monolayers (SAM) of 1,4-benzenedimethanethiol (BDMT) that can further anchor gold
\end{abstract}

nanoparticles (AuNPs) on the graphene surface. Raman spectroscopy and contact angle measurements confirm the SAM modification on graphene surface. AFM and XPS verify the anchoring of AuNPs on the graphene surface. Furthermore, the AuNPs-anchored BDMT-modified graphene (AuNPs/BDMT/G) electrode is explored for highly sensitive electrochemical detection of $\mathrm{H}_{2} \mathrm{O}_{2}$, exhibiting an impressive detection limit of $1.8 \mu \mathrm{M}$ (signal-to-noise ratio of 3$)$.
Electronic supplementary material The online version of this article (doi:10.1007/s40097-016-0201-6) contains supplementary material, which is available to authorized users.

\footnotetext{
Indrajit Shown

indrajit25@gmail.com

1 Institute of Atomic and Molecular Sciences, Academia Sinica, Taipei, Taiwan
} 


\section{Graphical abstract}
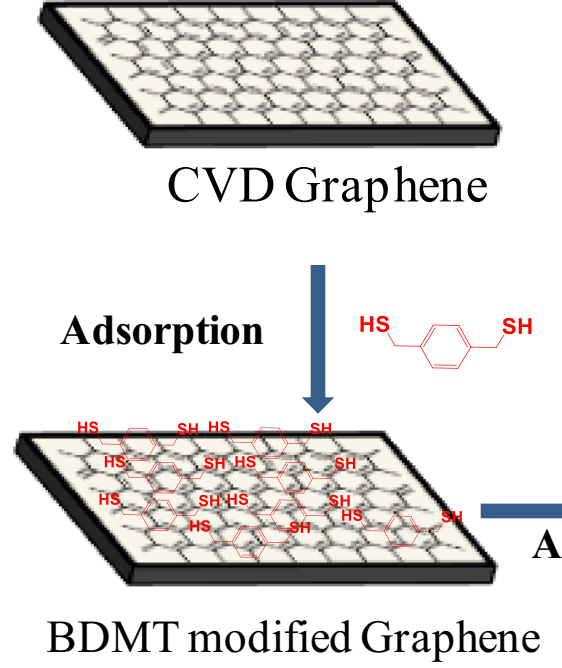

Keywords Graphene - Noncovalent functionalization · Self-assemble monolayer · Nanoparticles · Hydrogen peroxide biosensors $\cdot$ Electrochemical sensor

\section{Introduction}

In the recent years, graphene has been emerged as a most promising two-dimensional (2D) material of synthetic carbon allotrope's family. Since the discovery of graphene $[1,2]$, this one-atom thick honeycomb lattice has been investigated intensely in both the experimental and theoretical scientific studies because of its high electron mobility, large accessible surface area, excellent mechanical strength, thermal and optical properties [3-8]. It has shown potential applications in many areas such as nanoelectronics, catalysis, and batteries, supercapacitors, and sensors, etc [9-12]. Recently, graphene, mainly focused on graphene oxide (GO) or reduced graphene oxide (RGO), -based hybrid materials have been used in the development of high performance electrochemical biosensors as an advanced electrode [13-16]. However, the abundance of oxygen containing functional groups on the GO (or RGO) basal plane introduce a semiconducting nature which hinders the charge transfer process and hence the sensing performances.

Large scale graphene film has been successfully synthesized using the conventional thermal chemical vapor deposition (CVD) method, as reported in the literature [17, 18]. Functionalization of this CVD-grown 2D graphene is one of the important aspects to manipulate the intrinsic graphene properties (high conductivity and electron mobility) for its booming applications. The graphene sheet can be readily functionalized
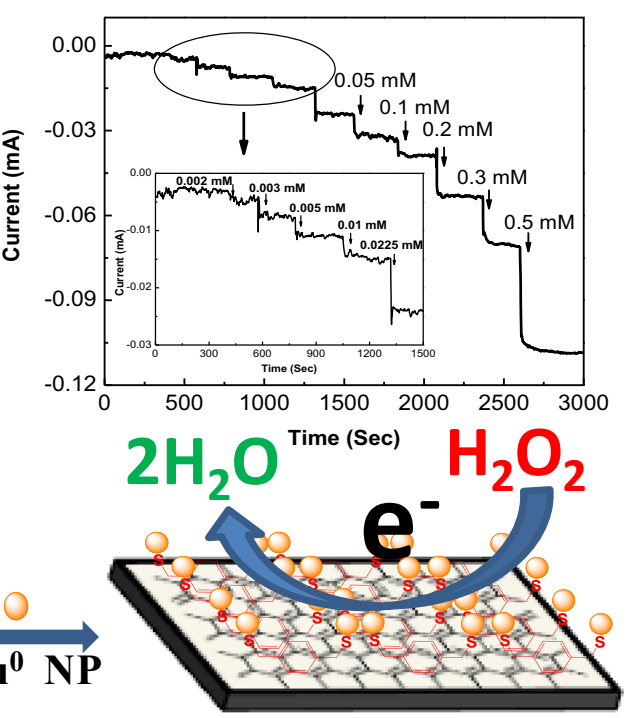

Au-NPs modified Graphene

via covalent $\mathrm{C}-\mathrm{C}$ coupling $[19,20]$ or non-covalent $\pi-\pi$ interaction [21, 22]. Modifying the graphene surface with desired functional groups by chemical treatment (covalent functionalization) is one of the convenient strategies to get well-dispersed functional groups on the graphene basal plane. However, such approaches lead to the presence of non-conducting agents on the graphene surface and the uncontrolled creation of defect sites that would undermine the electronic properties and alter the band structure of the pristine graphene $[19,20]$. Conversely, a non-covalent functionalization approach [21, 22] involving van der Waals forces or $\pi-\pi$ stacking of functionalizing moiety on the graphene sheet could provide selective functional groups on graphene surface's nearly perfect crystal structure retaining its intrinsic electronic properties and sensitivity. With recent development, the noncovalent functionalization routes have shown great potential for effective loading and easy manipulation, hence greatly adapted in a range of graphene-based applications. In biosensor applications, the immobilization of bio-molecules on the electrode surface is a critical step, whereas the metal nanoparticles (NPs) anchored via noncovalent modification on graphene surface can provide simple and highly active, though nonspecific, immobilization sites for bio-molecules.

Last few years, electrochemical hydrogen peroxide $\left(\mathrm{H}_{2} \mathrm{O}_{2}\right)$ sensor application has attracted extensive attention in the clinical, biological control and environmental protection fields [23-27]. In literature, highly sensitive and selective enzymes have been recommended as potential candidates to detect $\mathrm{H}_{2} \mathrm{O}_{2}$ [28-31]. In 2010, Zhou et al. [32] demonstrated a novel $\mathrm{H}_{2} \mathrm{O}_{2}$ biosensor, co-immobilizing horseradish peroxidase (HRP) with graphene into biocompatible polymer chitosan, with a detection limit of $1.7 \mu \mathrm{M}$ within a board linear 
range from 0.005 to $5.13 \mathrm{mM}$. However, enzymes are less appreciated for pragmatic applications due to their instability, high cost and complex immobilization process. As an alternative approach, non-enzymatic electrodes modified with metal NPs have been introduced as advanced $\mathrm{H}_{2} \mathrm{O}_{2}$ biosensor [33-36]. The metal nanoparticles are generally immobilized on the mesoporous materials by electrodeposition and solution process. Among the metal immobilization process, selfassembled monolayer (SAM) allowed the more control distribution of metals via electrostatic interaction without altering the conducting properties of the substrate. Here, we have developed an electrochemical sensor for $\mathrm{H}_{2} \mathrm{O}_{2}$ using self-assembled monolayers (SAM) modified CVD-grown graphene anchored with gold nanoparticles (AuNPs). At first stage, the SAM of 1,4-benzenedimethanethiol $\left(\mathrm{C}_{6} \mathrm{H}_{4}\left(\mathrm{CH}_{2-}\right.\right.$ $\mathrm{SH})_{2}$, abbreviated to BDMT), with double thiol ends on a single aromatic ring (Fig. 1), is formed on the surface of a CVD-grown graphene on $\mathrm{SiO}_{2} / \mathrm{Si}$ substrate. The non-covalent $\pi-\pi$ interaction between the aromatic rings of BDMT and graphene can provide thiol functional groups for AuNPs immobilization less affecting the intrinsic electronic properties of graphene. Subsequently, the AuNPs are anchored onto the basal plane of graphene utilizing the highly active thiol ends of BDMT via Au-S bond formation. The close proximity of AuNPs to the graphene basal plane through the short $\mathrm{Au}-\mathrm{S}-\mathrm{C}$ chains, along with the unique electronic properties of graphene, is expected to enhance the electron transfer pathway and hence the electrocatalytic activity. The aim of this study is to develop a simple strategy of noncovalent surface functionalization process via self-assembled monolayer formation on graphene followed by anchoring selective functional groups for the construction of the selective and sensitive electrochemical biosensor.

\section{Experimental}

\section{Non-covalent functionalization of CVD-grown graphene sheet}

A schematic representation of the non-covalent graphene functionalization with BDMT SAM and subsequent AuNPs anchoring is shown in Fig. 1, leading to the AuNPs- anchored BDMT-modified graphene (AuNPs/BDMT/G) electrode. Large scale graphene film has been synthesized by using the conventional CVD route [37]. Functionalization of graphene has been carried out according to the following steps: the CVD-grown single layer graphene transferred on $\mathrm{SiO}_{2} / \mathrm{Si}$ wafer is first immersed in a $1 \mathrm{mM}$ ethanolic solution of BDMT for $24 \mathrm{~h}$ under a nitrogensaturated condition, followed by washing with ethanol and drying under nitrogen flow. On the second step, the thiolfunctionalized graphene is immersed in a suspension of AuNPs (with an average size of 3-5 nm) for $6 \mathrm{~h}$, followed by washing with milliQ double distilled water and drying in a stream of nitrogen. Finally, the product is stored under vacuum. The detailed synthesis processes for the CVDgrown graphene [17,37] and AuNPs [38] are given in the supporting information.

\section{Results and discussion}

\section{Surface modified CVD-grown graphene}

Formation of the BDMT SAMs on CVD-grown graphene surface happens via a liquid-solid phase assembly, which provides thiol $(-\mathrm{SH})$ functional groups on the graphene surface via a non-covalent process. From the contact angle measurement, it is found that the BDMT-modified graphene (BDMT/G) exhibits increase in water contact angle in comparison with the pristine CVD-grown graphene (shown in Fig S1). The less electronegativity difference is expected between $\mathrm{S}-\mathrm{H}$ functional groups as compared to usual oxygen and hydrogen moieties observed on the graphene surface. Relatively less polar S-H groups increase the hydrophobicity of SAM-modified graphene.

To characterize the BDMT/G, Raman vibrational spectra for pristine and BDMT-modified graphene have been examined (Fig. 2a). Three characteristic peaks at 1325, 1579 and $2637 \mathrm{~cm}^{-1}$, observed for the pristine CVDgrown graphene, are assigned to the $\mathrm{D}, \mathrm{G}$ and $2 \mathrm{D}$ bands, respectively. With the BDMT functionalization, the $2 \mathrm{D}$ and $\mathrm{G}$ bands exhibit significant blue-shift to 2641 and $1583 \mathrm{~cm}^{-1}$, respectively. Bratescu et al. [39] reported the similar charge transfer phenomena on graphene due to

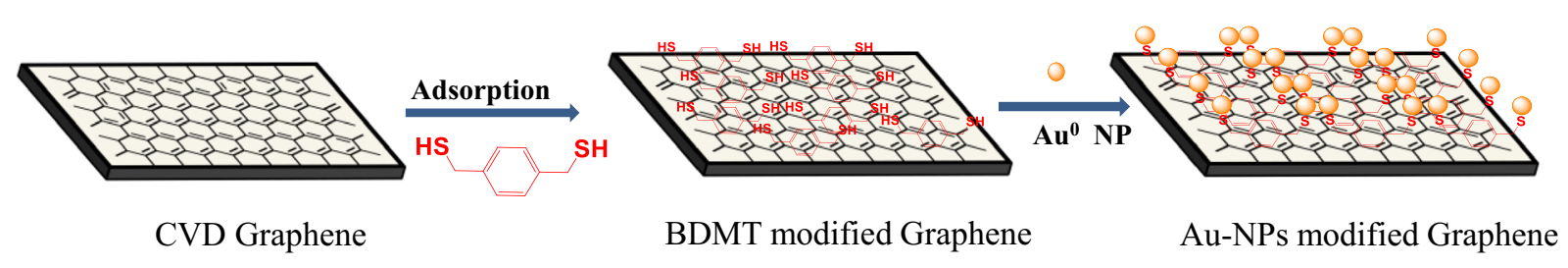

Fig. 1 Schematic representation of the functionalization steps for a CVD-grown graphene by non-covalent process (self-assemble monolayer formation) with Au nanoparticles (AuNPs) 

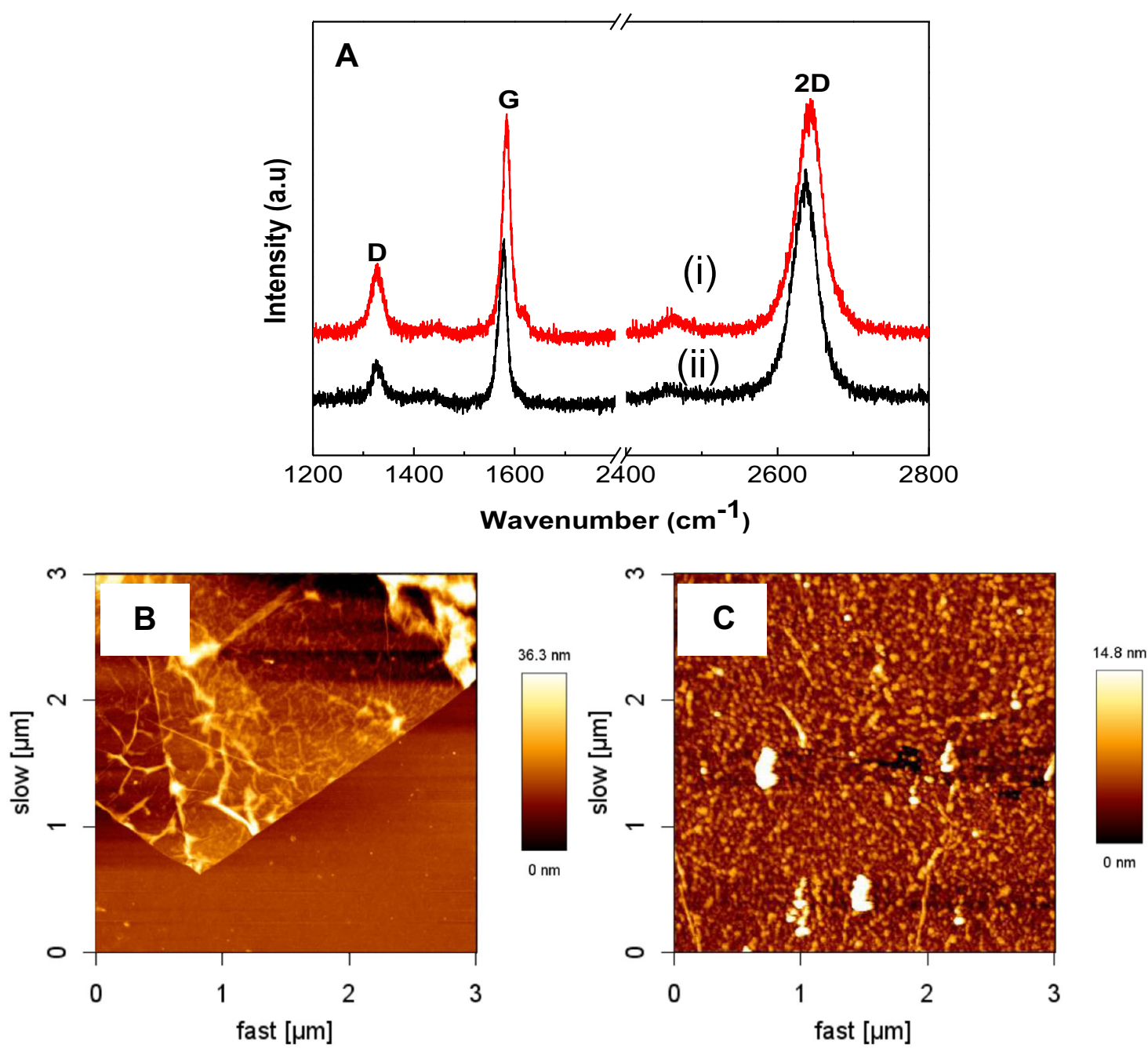

Fig. 2 a Raman Spectra of CVD-grown graphene (i) before and (ii) after the BDMT modification of CVD-grown graphene on $\mathrm{SiO}_{2} / \mathrm{Si}$ substrate. b, c AFM images of pristine and AuNPs-anchored BDMT-modified CVD-grown graphene

charge doping on large area graphene by gold alloy NPs. Furthermore, the BDMT modification on graphene leads to an increase in $I_{\mathrm{D}} / I_{\mathrm{G}}$ ratio and decrease in $I_{2 \mathrm{D}} / I_{\mathrm{G}}$ ratio, as listed in Table S1. Increase in D band intensity (or $I_{\mathrm{D}} / I_{\mathrm{G}}$ ratio) would be attributed to the enhanced disorder of graphene basal plane as a consequence of BDMT SAM formation on CVD-grown graphene surface. Interestingly, the decrease in $I_{2 \mathrm{D}} / I_{\mathrm{G}}$ ratio, along with the upshift of $2 \mathrm{D}$ and $\mathrm{G}$ bands, would indicate a doping effect in the graphene for BDMT/G. Such decrease of $I_{2 \mathrm{D}} / I_{\mathrm{G}}$ ratio can be quite likely attributed to a rise in the aromatic ring structures attached to the surface of graphene via $\pi-\pi$ interaction. These observations confirm the non-covalent SAM formation with BDMT molecules on the graphene surface. Further, the BDMT/G is subjected to the AuNPs functionalization that can also indirectly prove the SAM modification on graphene prior to the AuNPs anchoring. The pristine and AuNPs-anchored BDMT/G topographies are visualized in atomic force microscopy (AFM), shown in
Fig. 2b, c, which confirmed that AuNPs were uniformly distributed and anchored on the CVD-grown graphene surface.

To analyze the detail composition of the pristine CVDgrown graphene, BDMT/G and AuNPs/BDMT/G, X-ray photoelectron spectroscopy (XPS) analysis has been employed (Fig. 3). XPS spectrum of the CVD-grown graphene revealed $\mathrm{C} 1 \mathrm{~s}$ at $285.0 \mathrm{eV}$ which corresponds to $\mathrm{C}-$ $\mathrm{H}, \mathrm{C}-\mathrm{C}$, and $\mathrm{C}=\mathrm{C}$ bonds that are characteristic of graphite/graphene, additionally low \% of $\mathrm{C} 1 \mathrm{~s}$ occurred at $286.0 \mathrm{eV}$ which is characteristic of $\mathrm{C}-\mathrm{O}$ bonds. In comparison with the pristine CVD-grown graphene (Fig. 3a), the C1s XPS spectra of BDMT/G and AuNPs/BDMT/G reveal two components corresponding to different functional groups: $\mathrm{C}-\mathrm{C}(284.9 \mathrm{eV})$ of the $\mathrm{sp}^{2}$ carbons on the basal plane of the graphene sheets, and $\mathrm{C}-\mathrm{S}$ at $286.1 \mathrm{eV}$ (Fig. 3b, c). Interestingly, it can be noted that a small downshift of $\mathrm{C}=\mathrm{C}$ peak is observed in BDMT/G as compared to pristine CVD-grown graphene. This could be 

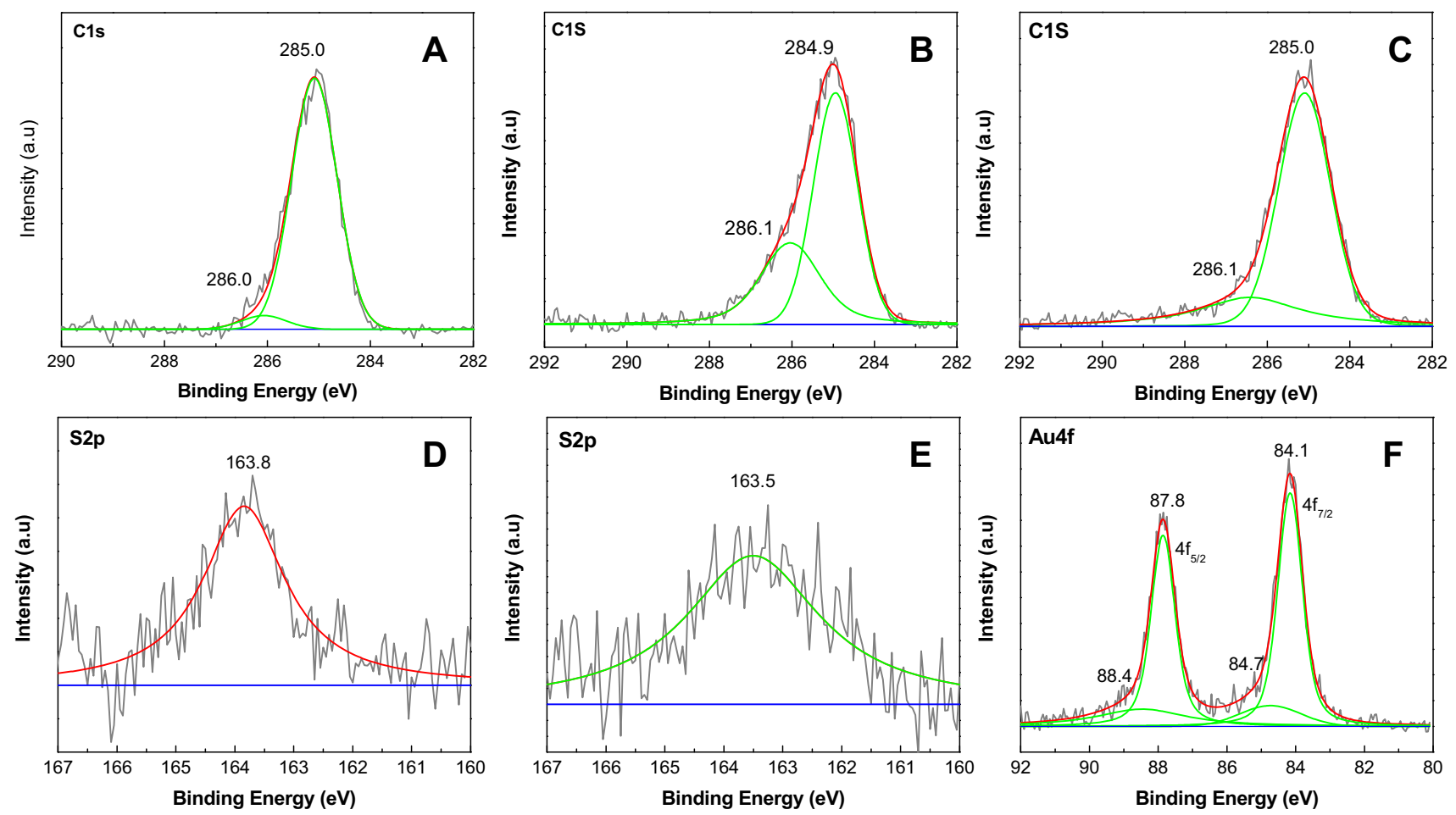

Fig. 3 X-ray photoelectron spectra: a-c C1S of pristine CVD-grown graphene, BDMT/G and AuNPs/BDMT/G, d-e S2p of BDMT/G and AuNPs/BDMT/G and f Au4f of AuNPs/BDMT/G

reasonably attributed to the interfacial charge transfer between the BDMT and graphene. The BDMT/G shows the specific S2p signal at $163.8 \mathrm{eV}$ ascribed to an unbound molecular thiol or disulfide (Fig. 3d), whereas AuNPs/ BDMT/G shows an additional small signal around 162.4 that attributes to the gold-bound thiol (S-Au, Fig. 3e). Furthermore, the AuNPs anchoring on SAM-modified graphene, via available thiol groups of BDMT, exhibits double Au4f XPS peaks around $84.1 \mathrm{eV}\left(4 \mathrm{f}_{7 / 2}\right)$ and $87.8 \mathrm{eV}\left(4 \mathrm{f}_{5 / 2}\right)$, as shown in Fig. 3f. Two additional humps at higher binding energy side for each of the deconvoluted $\mathrm{Au} 4 \mathrm{f}_{7 / 2}$ and $\mathrm{Au} 4 \mathrm{f}_{5 / 2}$ can be also observed those associate with the Au-S bonding. The above results demonstrate the covalent bonding of AuNPs to large area graphene surface via BDMT aromatic linker, which is consistent with the abovementioned AFM analysis data (Fig. 2b, c).

\section{Electrochemical properties of AuNPs/BDMT/G}

The electrochemical $\mathrm{H}_{2} \mathrm{O}_{2}$ sensing performance is usually investigated by monitoring the electro-reduction signal of $\mathrm{H}_{2} \mathrm{O}_{2}$. The $\mathrm{H}_{2} \mathrm{O}_{2}$ electro-reduction mechanism can be expressed as following:

$$
\begin{aligned}
& \mathrm{H}_{2} \mathrm{O}_{2}+\mathrm{e}^{-} \rightarrow \mathrm{OH}_{\mathrm{ad}}+\mathrm{OH}^{-} \\
& \mathrm{OH}_{\mathrm{ad}}+\mathrm{e}^{-} \rightarrow \mathrm{OH}^{-} \\
& 2 \mathrm{OH}^{-}+2 \mathrm{H}^{+} \rightarrow 2 \mathrm{H}_{2} \mathrm{O}
\end{aligned}
$$

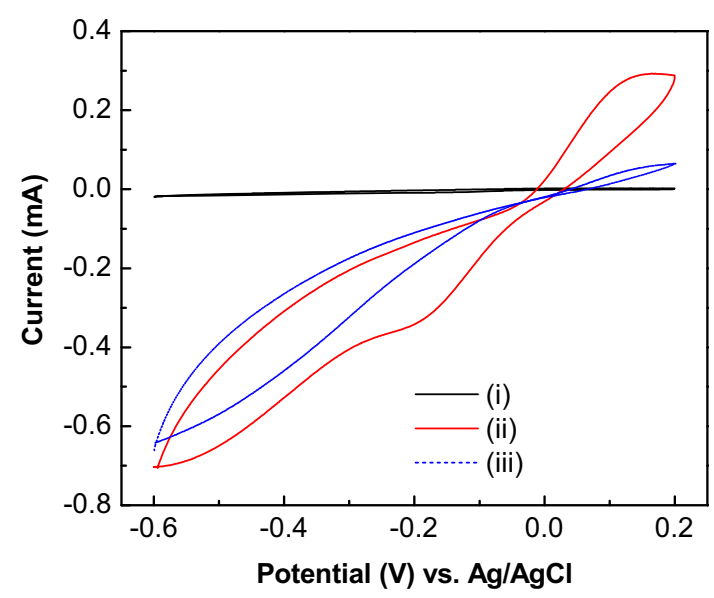

Fig. $4 \mathrm{CV}$ spectra of AuNPs/BDMT/G electrode in the (i) absence and (ii) presence of $2.5 \mathrm{mM} \mathrm{H}_{2} \mathrm{O}_{2}$ in $0.1 \mathrm{M}$ PBS $(\mathrm{pH}=7.4)$. For comparison, (iii) the same for a gold electrode is presented

Figure 4 shows the typical cyclic voltammograms (CV) of the AuNPs/BDMT/G electrode in absence and presence of $2.5 \mathrm{mM} \mathrm{H}_{2} \mathrm{O}_{2}$ in $0.1 \mathrm{M}$ PBS (pH 7.4) buffer solution, a standard gold electrode is used as a reference. In the absence of $\mathrm{H}_{2} \mathrm{O}_{2}$, no obvious reduction current can be observed for AuNPs/BDMT/G electrode, but with the addition of $\mathrm{H}_{2} \mathrm{O}_{2}(2.5 \mathrm{mM})$ the catalytic current increases with a reduction peak around $-0.2 \mathrm{~V}$ (vs. $\mathrm{Ag} / \mathrm{AgCl}$ ). However, the reference gold electrode shows a moderate 

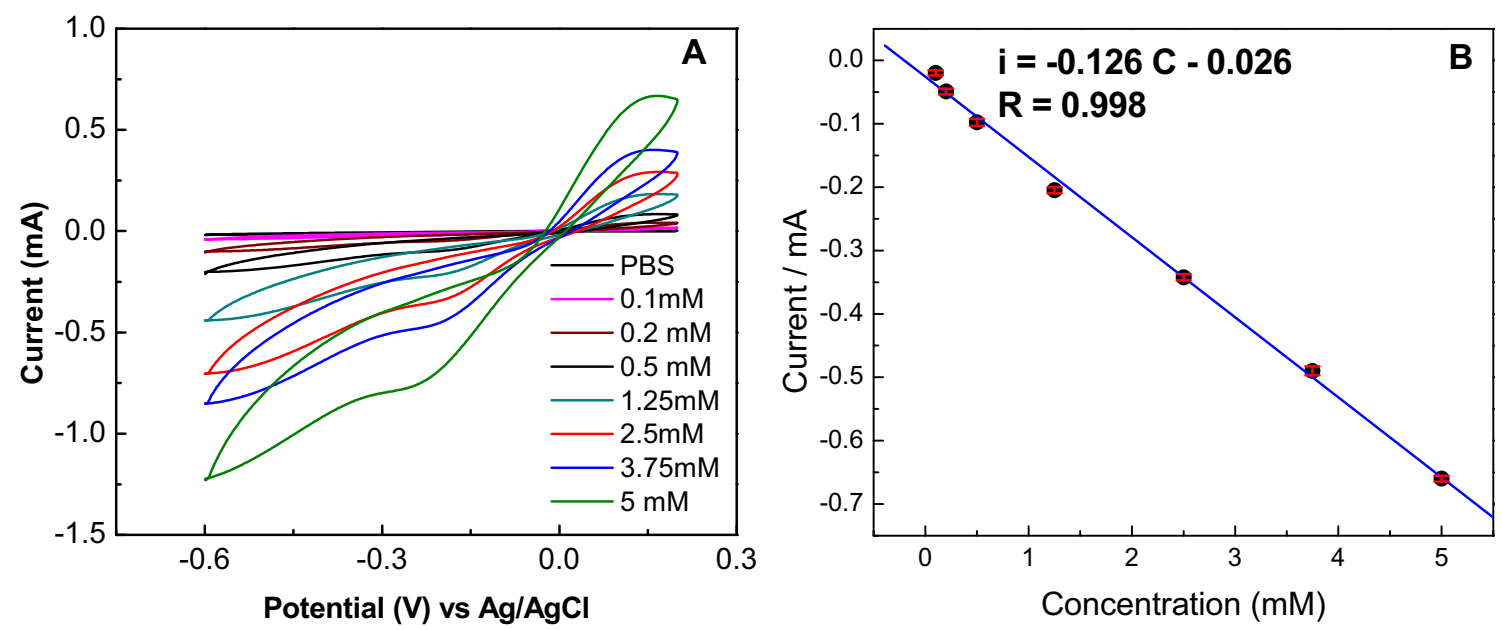

Fig. 5 a CV spectra of the AuNPs/BDMT/G electrode in $0.1 \mathrm{M}$ PBS (pH 7.4) with different $\mathrm{H}_{2} \mathrm{O}_{2}$ concentrations $(0,0.1,0.2,0.5,1.25,2.5$, $3.75,5 \mathrm{mM}$ ) at a potential scan rate $100 \mathrm{mV} \mathrm{s}^{-1}$. b Plot of current responses vs. $\mathrm{H}_{2} \mathrm{O}_{2}$ concentrations, at $-0.25 \mathrm{~V} \mathrm{vs}$. $\mathrm{Ag} / \mathrm{AgCl} \mathrm{RE}$

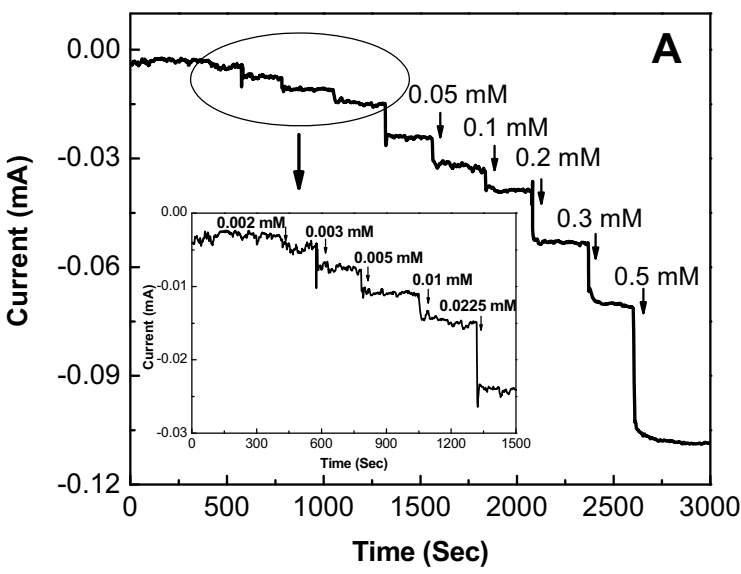

Fig. 6 a Dynamic response of the AuNPs/BDMT/G electrode on successive injections of $\mathrm{H}_{2} \mathrm{O}_{2}$ at different concentration, in $0.1 \mathrm{M}$ PBS ( $\mathrm{pH} 7.4$ ) at $-0.25 \mathrm{~V}$ vs. $\mathrm{Ag} / \mathrm{AgCl}$. The inset represents a

increase in the catalytic current with a reduction peak around $-0.25 \mathrm{~V}$ in the presence of $\mathrm{H}_{2} \mathrm{O}_{2}$. Figure 4 exhibits a drastic change in the CV spectra of AuNPs/BDMT/G when the $\mathrm{H}_{2} \mathrm{O}_{2}$ is added into buffer solution, revealing a superior catalytic behavior of AuNPs/BDMT/G based hybrid electrode.

Figure 5a displays the $\mathrm{CVs}$ of AuNPs/BDMT/G in $0.1 \mathrm{M}$ PBS ( $\mathrm{pH}$ 7.4) under various concentrations of $\mathrm{H}_{2} \mathrm{O}_{2}$. It is observed that both the reduction and oxidation currents increase steadily with increasing $\mathrm{H}_{2} \mathrm{O}_{2}$ concentrations. The reduction peak current value at $-0.2 \mathrm{~V}$ vs. $\mathrm{Ag} / \mathrm{AgCl}$ is chosen for the detection probe for $\mathrm{H}_{2} \mathrm{O}_{2}$ due to its sensitive response. The observed linear relation observed in Fig. 5b indicates that the reduction current is proportional to the concentration of $\mathrm{H}_{2} \mathrm{O}_{2}$ in a wide concentration range. Such observation supports an impressive electrocatalytic activity of the AuNPs/BDMT/G electrode.

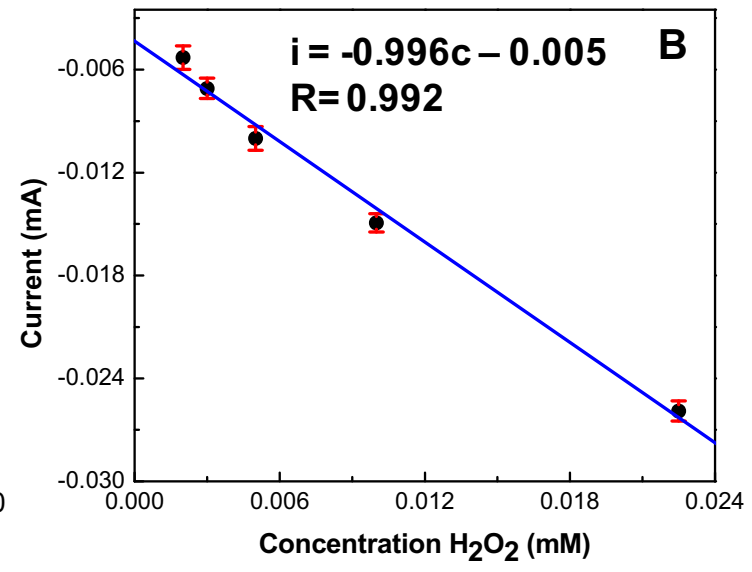

magnification of the data points obtained at low $\mathrm{H}_{2} \mathrm{O}_{2}$ concentrations. b Plot of current responses vs. $\mathrm{H}_{2} \mathrm{O}_{2}$ concentrations at lower concentration region

Typical dynamic response plot of AuNPs/BDMT/G electrode with successive addition of $\mathrm{H}_{2} \mathrm{O}_{2}$ is shown in Fig. 6a. The working potential is set at $-0.25 \mathrm{~V}$ as the reduction potential. The amperometric current measured at AuNPs/BDMT/G electrode responds directly with the concentrations of $\mathrm{H}_{2} \mathrm{O}_{2}$ exhibiting a wide linearity from 0.002 to $0.0225 \mathrm{mM}$ with a correlation coefficient of 0.992 as shown in Fig. 6b. The estimated detection limit is $1.8 \mu \mathrm{M}$, at a signal-to-noise ratio of 3 , which is found lower than other gold-based hydrogen peroxide biosensors [40, 41]. However, we believe that there is still room to improve the performance of our sensor. The overall electrochemical detection mechanism is based on the electrochemical reduction process. In the proposed solution-based surface modification or sensing process, it is hard to avoid the interfering components that can be oxidized as target analytes at particular potential. To compare the detection 
Table 1 Performances of various graphene-based hydrogen peroxide biosensors

\begin{tabular}{|c|c|c|c|c|}
\hline Electrode materials & Operating potentials $(\mathrm{V})$ & Linear range $(\mathrm{mM})$ & Limit of detection $(\mu \mathrm{M})$ & References \\
\hline Au-graphene-HRP-chitogen & -0.3 (vs. $\mathrm{Ag} / \mathrm{AgCl})$ & $0.005-5.13$ & 1.7 & [32] \\
\hline Pt/graphene nanocomposite & 0.02 (vs. SCE) & $0.0025-6.65$ & 0.8 & [42] \\
\hline Chitogen/AgNPs/graphene nanocomposite & $-0.5($ vs. $\mathrm{Ag} / \mathrm{AgCl})$ & $0.1-10$ & 7 & [43] \\
\hline $\mathrm{RGO} / \mathrm{Fe}_{3} \mathrm{O}_{4}$ nanocomposite & $-0.3($ vs. $\mathrm{Ag} / \mathrm{AgCl})$ & $0.1-6$ & 3.2 & [44] \\
\hline AuNPs/Prussian Blue/graphene nanocomposite & 0.1 (vs. $\mathrm{Ag} / \mathrm{AgCl}$ ) & $0.01-3$ & 1.5 & {$[45]$} \\
\hline AuNPs/BDMT/G & -0.25 (vs. $\mathrm{Ag} / \mathrm{AgCl}$ ) & $0.002-5$ & 1.8 & This work \\
\hline
\end{tabular}

limit of the AuNPs/BDMT/G with other graphene-based $\mathrm{H}_{2} \mathrm{O}_{2}$ biosensors, Table 1 lists the operating potential range, linear range, and sensitivity of different electrodes. All the data reveal that $\mathrm{H}_{2} \mathrm{O}_{2}$ biosensing parameters of the AuNPs/BDMT/G electrode are well comparable with the literature reports.

To study the reproducibility of AuNPs/BDMT/G electrode, repetitive amperometric current measurements were carried out in $0.02 \mathrm{mM} \mathrm{H}_{2} \mathrm{O}_{2}$ in PBS solution ( $\mathrm{pH}$ 7.4). The results of ten successive measurements show a relative standard deviation of $3.1 \%$. Also, the AuNPs/BDMT/G electrode shows high stability. To evaluate the stability of the graphene-based $\mathrm{H}_{2} \mathrm{O}_{2}$ sensor, the AuNPs/BDMT/G electrode was stored at $4{ }^{\circ} \mathrm{C}$ temperature and measured the amperometric current in the $0.02 \mathrm{mM} \mathrm{H}_{2} \mathrm{O}_{2}$ in PBS solution at intervals of a week, and it remained about $90 \%$ of its original sensitivity after 4 weeks. These studies implies that the AuNPs/BDMT/G electrode possess good stability and reproducibility.

\section{Conclusion}

In summary, we demonstrate AuNPs-modified noncovalent functionalized CVD-grown graphene electrode as a potential candidate for electrochemical $\mathrm{H}_{2} \mathrm{O}_{2}$ sensing application. Functionalization of graphene with 1,4-benzenedimethanethiol (BDMT) via non-covalent $\pi-\pi$ interaction between the aromatic rings can provide thiol functional groups for AuNPs immobilization without affecting the electronic properties of graphene. The anchored AuNPs on graphene can provide faster $\mathrm{e}^{-}$transfer due to the close proximity of AuNPs to the graphene basal plane through the short $\mathrm{Au}-\mathrm{S}-\mathrm{C}$ chain playing as highly active electrocatalytic sites for $\mathrm{H}_{2} \mathrm{O}_{2}$ detection. Using the amperometric method on the AuNPs/BDMT/G electrode, an $\mathrm{H}_{2} \mathrm{O}_{2}$ detection limit of $1.8 \mu \mathrm{M}$ can be achieved. We believe that this simple noncovalent modification strategy for large area graphene would open up new approach for graphene-based biosensor as well as other applications.
Acknowledgments We thank the Ministry of Science and Technology (MOST), Academia Sinica, Technical support from Nano-Core, the Core facilities for nanoscience and nanotechnology at Academia Sinica in Taiwan, is acknowledged.

Open Access This article is distributed under the terms of the Creative Commons Attribution 4.0 International License (http://crea tivecommons.org/licenses/by/4.0/), which permits unrestricted use, distribution, and reproduction in any medium, provided you give appropriate credit to the original author(s) and the source, provide a link to the Creative Commons license, and indicate if changes were made.

\section{References}

1. Novoselov, K.S., Geim, A.K., Morozov, S.V., Jiang, D., Zhang, Y., Dubonos, S.V., Grigorieva, I.V., Firsov, A.A.: Electric field effect in atomically thin carbon films. Science 306, 666-669 (2004)

2. Geim, A.K., Novoselov, K.S.: The rise of graphene. Nat. Mater. 6, 183-191 (2007)

3. Chang, C.K., Kataria, S., Kuo, C.C., Ganguly, A., Wang, B.Y., Hwang, J.Y., Huang, K.J., Yang, W.H., Wang, S.B., Chuang, C.H., Chen, M., Huang, C.I., Pong, W.F., Song, K.J., Chang, S.J., Guo, J.H., Tai, Y., Tsujimoto, M., Isoda, S., Chen, C.W., Chen, L.C., Chen, K.H.: Band gap engineering of chemical vapor deposited graphene by in situ BN doping. ACS Nano 7, 1333-1341 (2013)

4. Ren, W., Cheng, H.M.: The global growth of graphene. Nat Nano. 9, 726-730 (2014)

5. Ahn, J.H., Hong, B.H.: Graphene for displays that bend. Nat. Nano. 9, 737-738 (2014)

6. Perreault, F., Fonseca de Faria, A., Elimelech, M.: Environmental applications of graphene-based nanomaterials. Chem. Soc. Rev. 44, 5861-5896 (2015)

7. Chen, Y.C., Cao, T., Chen, C., Pedramrazi, Z., Haberer, D., de OteyzaDimas, G., Fischer, F.R., Louie, S.G., Crommie, M.F.: Molecular bandgap engineering of bottom-up synthesized graphene nanoribbon heterojunctions. Nat. Nano. 10, 156-160 (2015)

8. Hsu, A.L., Herring, P.K., Gabor, N.M., Ha, S., Shin, Y.C., Song, Y., Chin, M., Dubey, M., Chandrakasan, A.P., Kong, J., JarilloHerrero, P., Palacios, T.: Graphene-based thermopile for thermal imaging applications. Nano Lett. 15, 7211-7216 (2015)

9. Rodrigo, D., Limaj, O., Janner, D., Etezadi, D., García de Abajo, F.J., Pruneri, V., Altug, H.: Mid-infrared plasmonic biosensing with graphene. Science 349, 165-168 (2015)

10. Turcheniuk, K., Boukherroub, R., Szunerits, S.: Gold-graphene nanocomposites for sensing and biomedical applications. J. Mater. Chem. B. 3, 4301-4324 (2015) 
11. Raccichini, R., Varzi, A., Passerini, S., Scrosati, B.: The role of graphene for electrochemical energy storage. Nat. Mater. 14, 271-279 (2015)

12. Deng, D., Novoselov, K.S., Fu, Q., Zheng, N., Tian, Z., Bao, X.: Catalysis with two-dimensional materials and their heterostructures. Nat. Nano. 11, 218-230 (2016)

13. Ge, S., Lan, F., Yu, F., Yu, J.: Applications of graphene and related nanomaterials in analytical chemistry. New J. Chem. 39, 2380-2395 (2015)

14. Fang, Y., Wang, E.: Electrochemical biosensors on platforms of graphene. Chem. Commun. 49, 9526-9539 (2013)

15. Junhua, W., Jingjing, Q., Li, L., Liqiang, R., Xianwen, Z., Jharna, C., Shiren, W.: A reduced graphene oxide based electrochemical biosensor for tyrosine detection. Nanotechnology. 23, 335707 (2012)

16. Lim, S.A., Yoshikawa, H., Tamiya, E., Yasin, H.M., Ahmed, M.U.: A highly sensitive gold nanoparticle bioprobe based electrochemical immunosensor using screen printed graphene biochip. RSC Adv. 4, 58460-58466 (2014)

17. Li, X., Cai, W., An, J., Kim, S., Nah, J., Yang, D., Piner, R., Velamakanni, A., Jung, I., Tutuc, E., Banerjee, S.K., Colombo, L., Ruoff, R.S.: Large-area synthesis of high-quality and uniform graphene films on copper foils. Science 324, 1312-1314 (2009)

18. Hwang, J.S., Lin, Y.H., Hwang, J.Y., Chang, R., Chattopadhyay, S., Chen, C.J., Chen, P., Chiang, H.P., Tsai, T.R., Chen, L.C., Chen, K.H.: Imaging layer number and stacking order through formulating Raman fingerprints obtained from hexagonal single crystals of few layer graphene. Nanotechnology 24, 015702 (2013)

19. Shan, C., Yang, H., Song, J., Han, D., Ivaska, A., Niu, L.: Direct electrochemistry of glucose oxidase and biosensing for glucose based on graphene. Anal. Chem. 81, 2378-2382 (2009)

20. Lu, J., Do, I., Drzal, L.T., Worden, R.M., Lee, I.: Nanometaldecorated exfoliated graphite nanoplatelet based glucose biosensors with high sensitivity and fast response. ACS Nano $\mathbf{2}$, 1825-1832 (2008)

21. An, X., Simmons, T., Shah, R., Wolfe, C., Lewis, K.M., Washington, M., Nayak, S.K., Talapatra, S., Kar, S.: Stable aqueous dispersions of noncovalently functionalized graphene from graphite and their multifunctional high-performance applications. Nano Lett. 10, 4295-4301 (2010)

22. An, X., Butler, T.W., Washington, M., Nayak, S.K., Kar, S.: Optical and sensing properties of 1-pyrenecarboxylic acid-functionalized graphene films laminated on polydimethylsiloxane membranes. ACS Nano 5, 1003-1011 (2011)

23. Xin, Y., Fu-bing, X., Hong-wei, L., Feng, W., Di-zhao, C., Zhaoyang, W.: A novel $\mathrm{H}_{2} \mathrm{O}_{2}$ biosensor based on $\mathrm{Fe}_{3} \mathrm{O}_{4}-\mathrm{Au}$ magnetic nanoparticles coated horseradish peroxidase and graphene sheets-Nafion film modified screen-printed carbon electrode. Electrochim. Acta 109, 750-755 (2013)

24. Palanisamy, S., Cheemalapati, S., Chen, S.M.: Highly sensitive and selective hydrogen peroxide biosensor based on hemoglobin immobilized at multiwalled carbon nanotubes-zinc oxide composite electrode. Anal. Biochem. 429, 108-115 (2012)

25. Palanisamy, S., Chen, S.M., Sarawathi, R.: A novel nonenzymatic hydrogen peroxide sensor based on reduced graphene oxide/ $\mathrm{ZnO}$ composite modified electrode. Sens. Actuators B. Chem. 166, 372-377 (2012)

26. Chen, W., Cai, S., Ren, Q.Q., Wen, W., Zhao, Y.D.: Recent advances in electrochemical sensing for hydrogen peroxide: a review. Analyst. 137, 49-58 (2012)

27. Chen, S., Yuan, R., Chai, Y., Hu, F.: Electrochemical sensing of hydrogen peroxide using metal nanoparticles: a review. Microchim. Acta 180, 15-32 (2013)

28. Li, L., Xu, S., Du, Z., Gao, Y., Li, J., Wang, T.: Electrografted poly $(N$-mercaptoethyl acrylamide) and $\mathrm{Au}$ nanoparticles-based organic/inorganic film: a platform for the high-performance electrochemical biosensors. Chem. Asian J. 5, 919-924 (2010)

29. Zhang, L.: Direct electrochemistry of cytochrome $c$ at ordered macroporous active carbon electrode. Biosens. Bioelectron. 23, 1610-1615 (2008)

30. Wang, C.H., Yang, C., Song, Y.Y., Gao, W., Xia, X.H.: Adsorption and direct electron transfer from hemoglobin into a three-dimensionally ordered macroporous gold film. Adv. Funct. Mater. 15, 1267-1275 (2005)

31. Lu, X., Zhou, J., Lu, W., Liu, Q., Li, J.: Carbon nanofiber-based composites for the construction of mediator-free biosensors. Biosens. Bioelectron. 23, 1236-1243 (2008)

32. Zhou, K., Zhu, Y., Yang, X., Luo, J., Li, C., Luan, S.: A novel hydrogen peroxide biosensor based on Au-graphene-HRP-chitosan biocomposites. Electrochim. Acta 55, 3055-3060 (2010)

33. Li, S.J., Du, J.M., Shi, Y.F., Li, W.J., Liu, S.R.: Functionalization of graphene with Prussian blue and its application for amperometric sensing of $\mathrm{H}_{2} \mathrm{O}_{2}$. J. Solid State Electrochem. 16, 2235-2241 (2012)

34. Zhang, R., Chen, W.: Recent advances in graphene-based nanomaterials for fabricating electrochemical hydrogen peroxide sensors. Biosens. Bioelectron. (2016). doi:10.1016/j.bios.2016. 01.080

35. Xiao, F., Wang, L., Duan, H.: Nanomaterial based electrochemical sensors for in vitro detection of small molecule metabolites. Biotech. Adv. 34, 234-249 (2016)

36. Xing, L., Rong, Q., Ma, Z.: Non-enzymatic electrochemical sensing of hydrogen peroxide based on polypyrrole/platinum nanocomposites. Sens. Actuators B. Chem. 221, 242-247 (2015)

37. Hwang, J.Y., Kuo, C.C., Chen, L.C., Chen, K.H.: Correlating defect density with carrier mobility in large-scaled graphene films: Raman spectral signatures for the estimation of defect density. Nanotechnology 21, 465705 (2010)

38. Kuo, C.H., Chiang, T.F., Chen, L.J., Huang, M.H.: Synthesis of highly faceted pentagonal- and hexagonal-shaped gold nanoparticles with controlled sizes by sodium dodecyl sulfate. Langmuir 20, 7820-7824 (2004)

39. Bratescu, M.A., Saito, N.: Charge doping of large-area graphene by gold-alloy nanoparticles. J. Phys. Chem. C 117, 26804-26810 (2013)

40. Luo, J., Dong, M., Lin, F., Liu, M., Tang, H., Li, H., Zhang, Y., Yao, S.: Three-dimensional network polyamidoamine dendrimer$\mathrm{Au}$ nanocomposite for the construction of a mediator-free horseradish peroxidase biosensor. Analyst. 136, 4500-4506 (2011)

41. Gerlache, M., Senturk, Z., Quarin, G., Kauffmann, J.-M.: Electrochemical behavior of $\mathrm{H}_{2} \mathrm{O}_{2}$ on gold. Electroanalysis 9, 1088-1092 (1997)

42. Fengyuan, Z., Zaihua, W., Yuzhen, Z., Zhixiang, Z., Chunming, W., Yongling, D., Weichun, Y.: Microwave-assisted synthesis of $\mathrm{Pt} /$ graphene nanocomposites for nonenzymatic hydrogen peroxide sensor. Int. J. Electrochem. Sci. 7, 1968-1977 (2012)

43. Zhang, Y., Liu, S., Wang, L., Qin, X., Tian, J., Lu, W., Chang, G., Sun, X.: One-pot green synthesis of Ag nanoparticles-graphene nanocomposites and their applications in SERS, $\mathrm{H}_{2} \mathrm{O}_{2}$, and glucose sensing. RSC Adv. 2, 538-545 (2012)

44. Ye, Y., Kong, T., Yu, X., Wu, Y., Zhang, K., Wang, X.: Enhanced nonenzymatic hydrogen peroxide sensing with reduced graphene oxide/ferroferric oxide nanocomposites. Talanta 89, 417-421 (2012)

45. Xiaojun, Z., Jun, Z., Dongdong, Z., Guangfeng, W.: Electrodeposition method synthesise gold nanoparticles-Prussian bluegraphene nanocomposite and its application in electrochemical sensor for $\mathrm{H}_{2} \mathrm{O}_{2}$. Micro Nano Lett. IET 7, 60-63 (2012) 